\title{
Managing Death Fear: Book Review
}

\author{
Afreen Faiza \\ Ph.D. Scholar \\ Department of Psychology University of Karachi, Pakistan
}

\begin{abstract}
Choices of living: Coping with fear of dying is one of a comprehensive book which addresses the different ways to handle one's fear of death and dying. The book was written at the times when the United States of America was inflicted by terrorist activities, massive killings and other political upheavals this too possess an effect on the issues addressed in the present book. The book is a unique contribution in terms of its focus on different mechanisms for managing death fears.
\end{abstract}

Keywords: Fear of dying, Choices of living, coping with fear of death, managing fear of death

\section{INTRODUCTION}

There are many books which have been written on the topic of death, bereavement and other related issues. Choices of living: The language of the book is simple in which author skillfully explained complex and dark issues of death and dying with daily life examples. The book is divided into eighteen chapters a separate concluding chapter is also present which summarize descriptions of all chapters with final remarks by the author.

First chapter entitled Attitudes towards Death provided a description that death is an inherent reality for which all living beings possess awareness about the inevitable nature of death. This section included excerpts from popular writings of eminent scholars and poets which included the theme of death. It also described that fear of death is present across all tribes and religion. Fear of death is one of vital force which possesses a huge impact upon our lives and an exceptional fear of death is detrimental for psychological health. This was highlighted by an excerpt mentioned in this section as: " terror is even greater than anguish. It is anger and rage so intense as to paralyze all action against the assailant. It is fear of death incarnate.. (Foxe,1939, p.13). Fear of death is claimed as central fear for which we all strive to manage via different coping mechanisms. People connect their fears of death with daily life functioning in order to lead a life with meaning. In order to highlight the argument, the section included the examples of famous celebrities and their coping ways for the confrontation of death which culminated into proposed coping behaviors with ascending intensity to manage the fear of death.The theme of the book revolved around proposed positive and negative coping mechanisms for fear of death. Chapter II entitled The Probable Cause of the Fear of Dying. In this section, it was highlighted that fear of death is universal and instinctive. Humans possess the unique capability to anticipate death because of language capability. Children younger as three years old to show fear of death however it is debatable that either it is natural or learned from environment i.e. death of family member, pets and so on. Also in faints fear of death can emerge from momentary inattention by caregivers. This section elaborated the origins of fear of death as biologically programmed, learning as a result of experiences encountered in the different phase of life and early infantile encounters of abandonment or temporary separations from caregivers. These origins possess relevancy for preventive measures.

In Chapter III which entitled Creativity, the author claimed that creative endeavors provide a place through which we can take solace from death fears. It is a way via which one can attain symbolic immortality or in other words, author creative work in form of poems, monuments; sculptures enable artists to live in this world after their death. The author declared creativity as one of healthy defense mechanism to combat against existential threats. This 
International Journal of Science and Management Studies (IJSMS)

Volume: 01 Issue: 04
November to December 2018
E-ISSN: 2581-5946

www.ijsmsjournal.org

followed by Chapter IV: titled Love, in this section author, begins with Sternberg (1988) theory about love and elaborated the idea of love with the help of ideas put forth by other researchers. He claimed love provides a buffer against the fear of death. Feeling of love confers meaning in one's life which serves as a shield against death anxieties. Author of this book intellectually made linkages of love in different phases of life and described its importance for balanced mental health. He emphasized the love in different phases of life with the help of psychological theories and daily life examples. In infancy separation anxieties provide fertile grounds for death neurosis, this leads to the elaboration of pros and cons of sibling and Peer group love being part of some group mitigates the feeling of isolation and death fears. The author also has given considerable attention to the issue of romantic love and claimed it as most enduring love which provides an illusion for immortality thus serve as the powerful mechanism to fight against death terrors. To gravitate the arguments the author took support from Sternberg (1988) different types of love and simplify the concepts with daily life examples, excerpts from novels and lives of celebrities. He claimed that love has an exceptional power to provide peace and stability to griefstricken, terminally ill, mentally challenged and protect all from death anxieties. In the fifth Chapter of the book titled Humor, it was described that humor serves as a protective factor against death threats. Author classified humor into broad categories which included forms of humor which lessen the importance of death, diminish the significance of life, the fun of making facts about life after death, comedy as a form of therapy and jokes about uncertainty about time and place of death. In order to elaborate the issue in hand author made linkages with examples from psychological theories, the life of celebrities, movie characters and clinical cases. He claimed humor as one of acceptable coping mechanism which serves as medicine to fight against death anxieties. This section followed by chapter VI named Intellectualization. In this section, it was highlighted that intellectualization equip the individual to make a distance from death anxiety. It is not a mere accumulation and rote memorizing of facts and figures rather it involves gathering information about death and dying related matters in a meaningful way. The author expounds that intellectualization as one of positive coping tacit. It is an inner dialogue provides a chance for cognitive restructuring this shapes our attitudes towards death.

This section followed by the seventh Chapter entitled Procreation. The author described that genetic replication in form of one's offspring provides a shield against death fears. To gravitate argument author included excerpts from religious scripts which highlighted the significance of procreation discussion related political and social issues (contraceptives, test tube babies, abortion) provided strength to the fact that having one's children provides the feeling that we have the capacity to survive after our death. The writer of this book called procreation as one of positive defense action against mortality fears.

Chapter VIII titled Obsessive compulsive behavior in this portion, writer contended that obsessions and compulsions provide a way to lessen down death fears. He also included clinical cases an author's personal experiences to emphasize his arguments. Here writer noted that to some extent Work holism, orderliness and repetition is also important for healthy living. This followed by ninth chapter: Living life to the hilt, living better, living longer. The writer pointed out that living life to its full swing can be exhilarating however it has its own demerits over adopting a mediocre approach to spend life resources for having fun. The writer also contended that there are emphases to have prolonged life via life sustain drugs, beauty surgeries, and cosmetic treatments. Altogether these coping modes share a common goal which is to beat the terror of death.

Chapter ten is about Group membership it highlighted that sense of belongingness provides emotional warmth. The author explained that origin of group membership start from family child relates with mother and father and this continues to sense of belongingness to nation and tribes which provides the sense of immortality and act as a defense against death anxiety. Writer skillfully conveyed the idea of group membership with daily examples, personal experiences, political and social conditions of different countries and quotes from works of eminent 
International Journal of Science and Management Studies (IJSMS)

Volume: 01 Issue: 04
November to December 2018
E-ISSN: 2581-5946

www.ijsmsjournal.org

scholars. This followed by chapter XI: Religion. In this portion, writer contended that religion is one of the strongest coping mechanisms to fight against death terror. According to writer the functions of religion are multifaceted, it provides overarching coping modes which included a belief in life after death, sense of belongingness, metaphoric idea of an unseen world, confers purpose in life, chance for moral and ethical developments, forgiveness for one's misconducts and sinful behaviors all leads to combat against mortality terror. The writer penned down the sensitive issue of and its function in relation to death anxieties with scripts from Holy Bible.

Chapter XII entitled Mementos and Monuments, it was highlighted that tombs, mementos, Epitaphs and cemeteries all serve as a medium to combat against death fears. They are evident in almost every culture. "Probably the silliest work in which a human being can engage in the construction of a tomb for himself "(Iserson,1994,p.540). in this chapter writer highlighted the fact that humans tend to possess a wish to extend his journey after their death in form of tombs, sculptures, monuments also there is a tendency to write wills which include directions for significant others about management of life affairs like distribution of property and inheritance which serves as means to possess a sense of control after one's death. This followed by Chapter XIII Counter-phobic behavior, the writer highlighted the phenomenon that participating in life risk activities a way to attack one's mortality fears. Counter phonic behaviors provide a sense of control and mastery to individuals. The writer quoted Otto Fenichel (1939). It often happens that a person shows a preference for the very situations in which he is apparently afraid. And even frequently he will, later on, develop a preference for the situations which he formerly feared (Fenichel, 1939, p.264). The writer pointed out that risk-taking lies at the heart of Counter- phobic activities, individuals seek to repeatedly engage in such behaviors and release of tension provides pleasure and tends to become an addiction. He listed down several counter phobic acts and presented statistical findings of mortality rates occurred in different countries. The list of counter phobic acts includes skydiving, mountain climbing, skiing and snow sports, racing and car driving, motorcycle racing and miscellaneous risk-taking activities and also presented motivations for involvements in counter phobic acts. Writer contented that the engagements in counter phobic activities are the defense against death and serve as life-enhancing.

In subsequent chapters entitled Gambling, author contended that gambling serves as a defensive action that helps people to hide fears of death. We tend to absorb in games and it provides a way to forget fears of death at a particular moment. A separate chapter described dissociation as another defense mechanism in which fear of death is pushed out from the awareness to unconscious state. It is an altered state of mind writer provided different cases of dissociative personality disorder and elaborated it with examples, use of drugs hypnotic trance, fugue, meditation to induce a cutoff from reality. Dissociation in form of movies and literature serves as a controlling factor for fear of death. In another section of book, denial, and repressions highlighted as important defense mechanisms which equip us to stay sane and provide an ability to fight from awareness of death which is undoubtedly a painful reality. In everyday life, repressions are evident in form of euphemisms and humor about death and its related affairs. In western culture, death is represented by the words “pass on" " end of your days" (Feifel, 1959, p. 115).

A substantial attention has been given to issue of homicide in an independent chapter entitled suicide, writer believed that suicide is a way via individuals can exercise control over death and it is an unhealthy defense mechanism to combat against the fear of death. In order to understand the motives behind suicidal acts writer presented case examples of individuals who committed suicide. a brief psychological and social perspective of suicide was also described in this section. Considerable attention has been given to Durkheim's sociological analysis of suicide (1897) which categorized suicide into different categories (anomic, altruistic, egoistic and fatalistic ). The writer also highlighted assisted suicides and other self-destructive behaviors. He contended that suicide is an insoluble dilemma which stems out from the constricted vision of suicidal individuals. In last chapter 
projection, killing and problem of evil writer creatively made linkages among three concepts. He contended that killing others serves a symbolic immortality and a victory over death which cause wars and massive killings in nations. Individuals project inner dark selves towards the devil, destructive nature or Punishments from God which is evident in different religions in form of animal sacrifice, exorcism and human sacrifice. When we feel dirty inside we find solace by sacrificing the lives of others. Becker in 1976 poised that "Evil comes from man's urge to heroic victory over evil"'(p.136). In this chapter, Writer provided examples from literature, psychological and philosophical concepts which increased the richness of phenomenon. This section culminated into summary and conclusion section in which the author briefly made general remarks about death. He contended that death and life are intertwined and a belief after death is an illusion to fight against death fears, death fears shaped by learning process and death experiences. Writer again listed coping methods of death and described shortly in this section and supports his arguments with different examples.

\section{CONCLUSIONS}

Coping with fear of dying is a worthwhile contribution for students, academicians, philosophers, psychologists, sociologists to understand, explore death and dying issues and design therapeutic techniques in clinical settings. It aspires to benefit common readers to get an insight about different coping tacit to address and manage personal death fears.

\section{REFERENCES}

[1] Becker, E.(1976). Escape from evil (EFE). New York: The Free Press.

[2] Durkheim,e. (1897).Le Suicide, edude de sociologie(J. Spaulding and G. Simpson, trans.) (also English translation, NewYork, free press, 1951 ed.). Paris; Alcan.

[3] Feifel, H.( 1959). Attitudes towards death in some normal and mentally ill populations. In H. Feifel (Ed.), The Meaning of Death. New York: McGraw- Hill, pp. 114-130.

[4] Fenichel, O. (1939). the counterphobic attitude. International Journal of Psycho-Analysis, 20,263-274.

[5] Foxe, A. N. (1939). The life and Death Instincts. New York: The Monograph Editions.

[6] Iserson, K. V. (1994). Death to Dust: What Happens to Dead Bodies? Tucson, AZ: Galen Press.

[7] Langer,T.S.(2002). Choices for Living Coping with Fear of Dying Introduction. US:Springer Publishers ,pp. pp XV, 308.

[8] Sternberg, R.J. a. M.L.B. (Ed.) (1988). The Psychology of Love. New Haven: Yale University Press. 